\title{
COMPOSTOS ALELOPÁTICOS EM BRACHIARIA spp. E SUA INTERAÇÃO COM BACTÉRIAS DIAZOTRÓFICAS ASSOCIATIVAS
}

\author{
TOLEDO, Carla Neves ${ }^{1}$ \\ DIAS E SILVA, Nhayandra Christina ${ }^{2}$ \\ FLORENTINO, Ligiane Aparecida ${ }^{2}$ \\ REZENDE, Adauton Vilela de ${ }^{2}$
}

\begin{abstract}
RESUMO: O Brasil possui cerca de 172,3 milhões de hectares de pastagens, sendo que cerca de $85 \%$ são constituídas por forrageiras do gênero Brachiaria, devido à sua alta adaptabilidade às diferentes condições edafoclimáticas. Dessa forma, essas plantas desempenham papel fundamental nos sistemas extensivos e semiextensivos de produção animal. No entanto, cerca de $70 \%$ destas áreas encontram-se degradadas, devido, principalmente, à falta de adubação de manutenção. Uma das alternativas para substituir o uso de fertilizantes nitrogenados consiste no uso de bactérias diazotróficas, as quais realizam a fixação biológica de $\mathrm{N}_{2}(\mathrm{FBN})$, podendo fornecer parcialmente o nitrogênio exigido pela cultura. Entretanto, os estudos de FBN em Brachiaria spp. não tem apresentado grande contribuição, tornando-se necessário a realização de novas pesquisas visando selecionar estirpes inoculantes para as espécies deste gênero. Além disso, sabe-se que estas plantas produzem compostos alelopáticos, os quais podem influenciar negativamente, a sobrevivência das bactérias diazotróficas na rizosfera. Baseando-se nisso, os objetivos desta revisão foram: abordar a importância de Brachiaria spp na produção animal, apresentar os compostos alelopáticos liberados pelas plantas desse gênero e a influência destes na associação de bactérias diazotróficas associativas com estas plantas.
\end{abstract}

Palavras-chave: Fixação Biológica de Nitrogênio. Gramíneas Forrageiras. Produção Animal.

\section{ALLELOPATHIC COMPOUNDS IN BRACHIARIA SPP. AND INTERACTION WITH ASSOCIATIVE DIAZOTROPHIC BACTERIA}

\begin{abstract}
SUMMARY: Brazil has about 172.3 million hectares of pasture, and about $85 \%$ are made up of forages of the genus Brachiaria, due to their high adaptability to different soil and climatic conditions. Thus, these plants play a fundamental role in the extensive and semi-extensive systems of animal production. However, about $70 \%$ of these areas are degraded, mainly due to the lack of maintenance fertilization. One of the alternatives to replace the use of nitrogen fertilizers is the use of diazotrophic bacteria, which perform the biological fixation of $\mathrm{N}_{2}$ (BFN), and can supply part of the nitrogen required by the crop. However, BFN studies in Brachiaria spp. has not presented great contribution, making it necessary to carry out new research in order to select inoculant strains for the species of this genus. In addition, it is known that these plants produce allelopathic compounds, which may negatively influence the survival of diazotrophic bacteria in the rhizosphere. Based on this, the objectives of this review were: to address the importance of Brachiaria spp in animal production, to present the allelopathic compounds released by plants of this genus and their influence on the association of diazotrophic bacteria with these plants.
\end{abstract}

Keywords: Animal Production. Biological Nitrogen Fixation. Forage Grasses.

\section{INTRODUÇÃO}

Diversos são os gêneros de gramíneas forrageiras tropicais que se apresentam como opções para a formação de pastagens no Brasil. Dentre estes, as espécies de Brachiaria destacam-

\footnotetext{
${ }^{1}$ Departamento Bioquímica e Microbiologia da Unifenas- Programa de Pós Graduação em Ciência Animal ${ }^{2}$ Programa de Pós Graduação em Ciência Animal
} 
se como uma das forrageiras mais cultivadas devido à sua adaptação às diferentes condições edafloclimáticas e de manejo da pastagem (ALMEIDA et al., 2016). Além disso, a pastagem de Brachiaria spp. quando bem manejada possui valores nutricionais capazes de proporcionar ganho animal, apresentando maior viabilidade econômica (BARROS, et al., 2017; TOLK et.al., 2013).

No entanto, verifica-se que grande parte das pastagens cultivadas com Brachiaria spp. se encontram degradadas (JABRAN et al., 2015), devido a fatores diversos, como: falta de adubação de manutenção, superpastejo, métodos de plantio e época de semeadura inadequados, baixo vigor das sementes, ocorrência de pragas e uso da pastagem acima da capacidade de suporte (DALEY et al., 2010). Segundo Machado et al. (2011), um dos fatores que impedem a sustentabilidade das pastagens se deve ao uso de germoplasma inadequado à região, práticas incorretas de manejo do solo, excesso de animais e determinadas práticas como o uso do fogo. Com isso verifica-se redução na produtividade e a ocorrência de impactos ambientais negativos associado ao processo de degradação (CAZETA et al., 2008; WESTON et al.,2013).

A pecuária constitui a principal atividade emissora de gás metano $\left(\mathrm{CH}_{4}\right)$ no Brasil, contribuindo também para emissão de dióxido de carbono $\left(\mathrm{CO}_{2}\right)$ e óxido nitroso $\left(\mathrm{N}_{2} \mathrm{O}\right)$ (BRASIL, 2016). Nesse sentido, os processos mitigatórios na atividade agropecuária estão relacionados ao emprego de técnicas visando a recuperação destas áreas, dentre as quais podemos destacar a fixação biológica de nitrogênio (FBN) e a integração Lavoura-Pecuária-Floresta (ILPF) (ELOY, 2013).

A FBN constitui numa das alternativas sustentável e de baixo custo, visto que pode reduzir totalmente ou parcialmente a adubação com fertilizantes nitrogenados. $\mathrm{O}$ processo de FBN é realizado por bactérias do solo que possuem a enzima nitrogenase, a qual reduz o $\mathrm{N}_{2}$ a amônia $\left(\mathrm{NH}_{3}\right)$ (SANDINI, et al. 2011). Entretanto, a contribuição da FBN para o gênero Brachiaria não têm sido tão significativa, quando comparadas à outras espécies vegetais, como no milho e trigo (HUNGRIA, 2013).

As plantas do gênero Brachiaria produzem diversos compostos alelopáticos (ARMERO et al., 2011), os quais são liberados pelos vegetais no ambiente e podem atrair, repelir, nutrir ou promover toxicidade no desenvolvimento de outras plantas e microrganismos, podendo interferir de forma benéfica ou não, no desenvolvimento de outras espécies (LUVEZUTI et al.,2014; CARVALHO; PIRES, 2018).

Considerando a importância que os agentes aleloquímicos liberados pelas gramíneas e a escassez de informações que abordam a relação entre os aleloquímicos e as bactérias fixadoras de $\mathrm{N}$, objetivou-se com essa revisão de literatura abordar sobre a importância de Brachiaria spp. na produção animal, apresentar os compostos alelopáticos liberados pelas plantas desse gênero e a influência destes na associação de bactérias diazotróficas associativas com estas plantas. 


\section{REVISÃO DE LITERATURA}

\subsection{Brachiaria spp.}

O gênero Brachiaria (sinonímia Urochloa) é classificada na divisão como Angiospermae, da classe Monocotiledônea, ordem Graminales, família Poaceae, subfamília Brachiareae, gênero Brachiaria (GASTAU; NELSON, 1994). Este gênero é originário da África e no Brasil, os primeiros exemplares de espécies do gênero foram trazidos na época colonial quando a palha de Brachiaria mutica foi utilizado como leito para escravos em navios negreiros. A introdução oficial na agropecuária de Brachiaria spp. no país ocorreu com B. decumbens, no Instituto de Pesquisa Agropecuária do Norte (IPEAN) (BALNEVARA et al., 2012) e atualmente estima-se que a área de pastagem de Brachiaria sp. seja cerca de 170 milhões de hectares (CASTRO et al., 2016).

A temperatura ideal para o crescimento é $30-35^{\circ} \mathrm{C}$ e a temperatura mínima é de $15^{\circ} \mathrm{C}$ (JORGE; SOUZA, 2015), fatores estes que fazem com que este gênero seja amplamente utilizado nas pastagens. Além disso, apresenta tolerância a baixa fertilidade do solo, elevada produtividade e alto valor nutritivo, sendo estas características desejáveis à produção animal brasileira (ALMEIDA et al., 2010). Torna-se importante ressaltar que a produtividade e a qualidade de Brachiaria spp., são influenciadas pela espécie e pelo cultivar, pelas propriedades químicas e físicas do solo, pelas condições climáticas, idade fisiológica e pelo manejo a qual é submetida. Na tabela 1 estão apresentados os genótipos e espécies mais cultivados no Brasil.

Tabela 1: Lista dos genótipos com os nomes da cultivar e sua respectiva espécie.

\begin{tabular}{ccc}
\hline $\mathbf{N}^{\circ}$ & Genótipos & Espécie \\
\hline 1 & 'Basilisk' & Brachiaria decumbens \\
2 & 'Marandu' & Brachiaria brizantha \\
3 & 'Xaraés' & Brachiaria brizantha \\
4 & 'BRS Piatã' & Brachiaria brizantha \\
5 & BRS (acesso) & Brachiaria brizantha \\
6 & HBCG331 (Híbrido) & B. brizantha x B. ruziziensis \\
7 & HBCG336 (Híbrido) & B. brizantha x B. ruziziensis \\
8 & 'Llanero' & Brachiaria humidicola \\
9 & 'Tully' & Brachiaria humidicola \\
10 & 'BRS Tupi' & Brachiaria humidicola \\
11 & 'HH3 (Híbrido) & Brachiaria humidicola \\
12 & HH146 (Híbrido) & Brachiaria humidicola \\
13 & HH216 (Hídrido) & Brachiaria humidicola \\
14 & HH350 (Híbrido) & Brachiaria humidicola \\
\hline
\end{tabular}

Fonte: Adaptado segundo Bianchi et al.(2002). 
As cultivares Marandu, Xaraés e Piatã de B. brizantha., constituem opções de forrageiras que visam atender às necessidades de diversificação de pastagens. Dentre essas, a que mais se destacou foi a Marandu. A Piatã foi lançada em 2006, apresenta boa produtividade e mais resistente à seca do que o Marandu e a Xaraés (BORELA et al., 2009; ADAMI et al., 2012).

Teodoro et al. (2015), afirmam que as gramíneas forrageiras dos gêneros Brachiaria e Panicum, vem sendo estudadas no desenvolvimento de novas cultivares, visando à redução da vulnerabilidade dos sistemas de produção por apresentarem boa produtividade e alto desempenho.

\subsection{Alimentação Animal e Toxicidade}

As pastagens representam as formas economicamente mais viáveis de alimentação animal, contribuindo significativamente na dieta do rebanho. Nesse sentido, destaca-se Brachiaria spp., gramínea que apresenta características como alta produção de biomassa, boa adaptação aos diversos tipos de solos. Forrageira tradicionalmente usada para corte, atualmente é crescente o interesse dos pecuaristas pela sua utilização sob pastejo (NEVES et al., 2010).

A Brachiaria apresenta alguns problemas, dentre eles casos de fotossensibilização, que se caracteriza por uma sensibilidade exagerada dos animais aos raios solares e pode ser classificada como primária ou secundária (hepatógena), ambas relacionadas à presença do agente fotossensibilizador e tem importância significativa pois o conhecimento da doença por parte dos pecuaristas contribui para o seu controle. É observada em pastagens de Brachiaria spp. e vem sendo atribuída à toxina esporodesmina produzida por esporos do fungo Pithomyces chartarum nas pastagens. Atualmente, a toxicidade para animais em pastagens de Brachiaria spp. é atribuída presença de saponinas esteroidais litogênicas na própria gramínea (BATTISTUS; INAGAKI, 2016).

A utilização de ensaios biológicos vegetais para o monitoramento da bioatividade de extratos, frações e compostos isolados de plantas têm sido frequentemente incorporados à identificação e monitoramento de substâncias potencialmente tóxicas, gerando um problema significativo, pois os danos provocam graves perdas econômicas para a indústria e afetam a produção animal (ALMEIDA et al., 2016).

Os primeiros relatos, ocorreram em $B$. decumbens e está associada à presença de Pithomyces chartarum, mas posteriormente foi demonstrado que a intoxicação em ruminantes é causada por de saponinas esteroidais litogênicas presentes na planta. Além da fotossensibilização, descreve-se, na intoxicação por B. decumbens, uma síndrome de emagrecimento progressivo, dermatite, retração cicatricial auricular, icterícia, corrimento ocular, crostas auriculares e 
oculares, e ulcerações na parte ventral da língua. As lesões histopatológias muitas vezes não determinam sinais clínicos ou, alterações macroscópicas, porém afetam o funcionamento do órgão causando baixo ganho de peso. A morbidade varia de $0,2 \%$ a $50 \%$ e a letalidade de $44,4 \%$ a 100\% (INSTITUTO BRASILEIRO DE GEOGRAFIA E ESTATÍSTICA, 2007). Considerando o sistema de produção, percebeu-se que são mais frequentes em animais em regime extensivo em detrimento do semi-intensivo e intensivo (MATTIELLO et al., 2008).

\section{3 Alelopatia}

A alelopatia foi descrita por Molisch (1937), como substancias orgânicas sintetizadas por diferentes espécies que podem inibir ou estimular outros indivíduos. Tais compostos, são encontrados e distribuídos em concentrações variadas nas diferentes partes da planta e ao longo do seu ciclo de vida, desde a germinação, desenvolvimento e senescência e, também, com as condições nas quais as plantas se encontram (CARVALHO et al., 2008; LUVEZUTI et al, 2014).

Os compostos alelopáticos tem sido estudado devido sua importância como mecanismo de defesa à microrganismos patogênicos e atividade herbicida, inseticida e nematicida (WESTON et al., 2013).

As principais rotas biossintéticas de produção dos metabólitos secundários envolvem as vias do acetato, do ácido chiquímico e do mevalonato, que são usados na síntese dos terpenoides em específico (JABRAN et al., 2015), conforme esquema apresentado na Figura 1.

Figura 1: Formação de compostos secundários nas plantas.

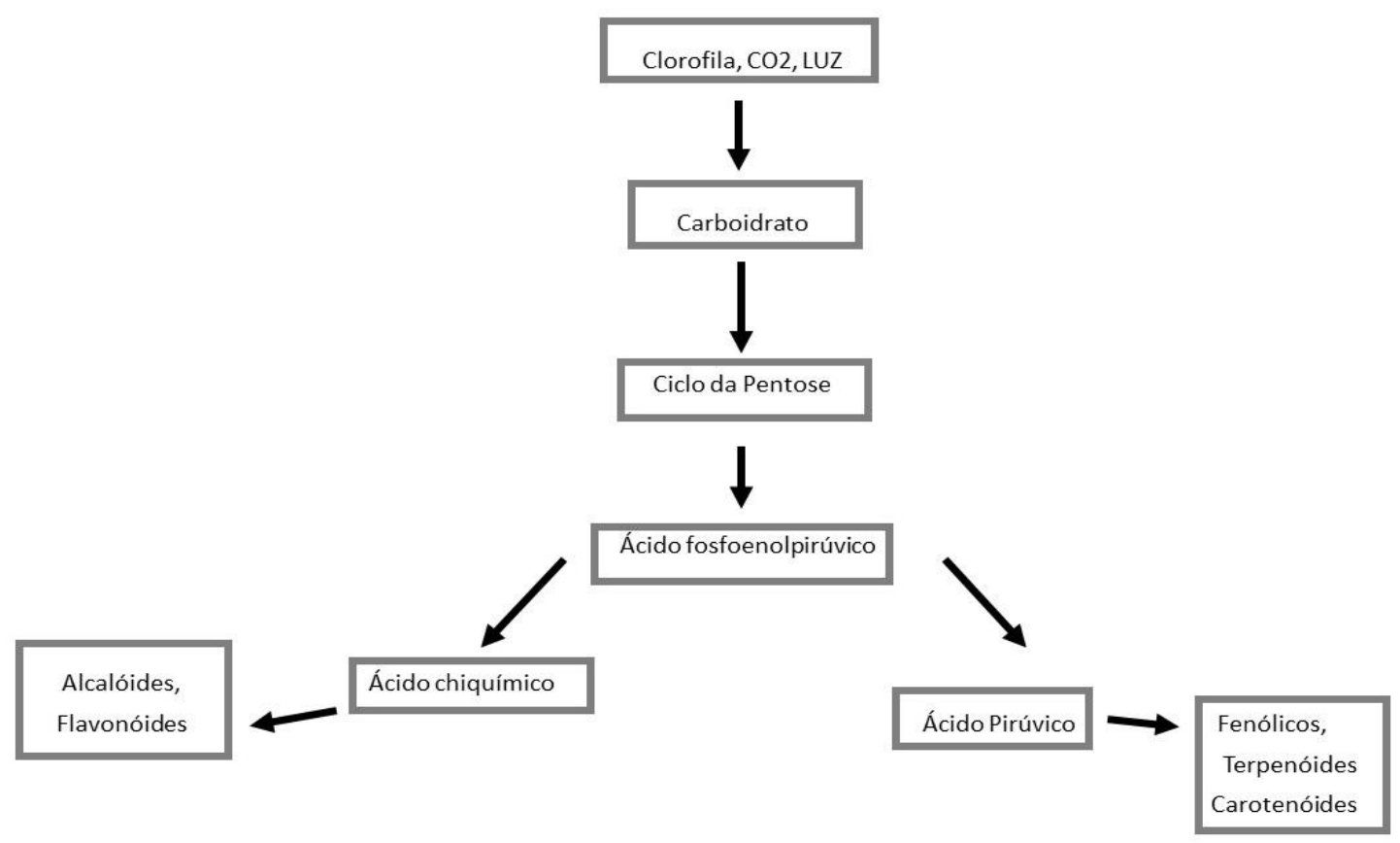

Fonte: Adaptado segundo Brooks; Feeny (2004). 
Muitos compostos secundários pertencentes a diversas classes como fenóis, terpenos, alcalóides, benzoxazinoides, taninos, cumarinas, resinas glicosídicas, esteróides, flavonóides, poliacetilenos, ácidos graxos, aminoácidos não proteicos, lipídeos e peptídeos mediam os efeitos alelopáticos (MOKHTARI et al., 2015), e as principais formas de liberação dessas substâncias ocorrem por meio dos processos de volatilização, exsudação, lixiviação e decomposição dos resíduos (RASHID et al., 2010), envolvendo a complexa cadeia de comunicação química entre as espécies (MACHADO et al., 2011).

A disponibilidade dos aleloquímicos para absorção dependerá dos processos de interação destes com o ambiente. Essas substâncias estão sujeitas aos processos de degradação por decomposição microbiana, fotólise, oxidação, adsorção e volatilização (RICE, 1984).

A produção de agentes aleloquímicos pode ser regulada por diversos fatores, como a temperatura, disponibilidade de água e nutrientes, microrganismos presentes, dentre outros (TOLK et al., 2013). Adicionalmente, os fatores interligados ao estresse vegetal podem aumentar a atividade biológica referente aos aleloquímicos. A resistência ou tolerância a estes compostos é uma característica espécie-específica, existindo aquelas mais sensíveis (FELIX, 2012).

Grande parte dos resultados encontrados na literatura apontam para efeitos nos quais as substâncias químicas com propriedades alelopáticas isoladas não apresentam potencial alelopático significativo (FIETZ, 2008; BORGES, 2014; ALMEIDA, 2016). Os trabalhos de BULEGON et al. (2016) são exemplos desse tipo de abordagem. Propõe-se que tais substâncias atuam em conjunto, pois a concentração, dobra em relação àquela de cada substância isoladamente. Os autores afirmam que as espécies receptoras podem ser devidas aos compostos pertencentes ao grupo dos flavonoides, ácidos fenólicos e ácidos carboxílicos.

\subsection{Compostos Alelopáticos Produzidos por Brachiaria spp.}

As plantas do gênero Brachiaria produzem compostos aleloquímicos (FAVARETTO et al., 2018), de acordo com informações das tabelas 2 e 3. 
Tabela 2. Características gerais dos estudos sobre compostos alelopáticos conduzidos com gramíneas cultivadas no Brasil.

\begin{tabular}{|c|c|c|c|c|}
\hline Espécies & Orgão vegetal & Espécies-alvo & Efeito & Referências \\
\hline $\begin{array}{l}\text { Brachiaria } \\
\text { brizantha }\end{array}$ & $\begin{array}{l}\text { Sementes, brotos } \\
\text { e raízes }\end{array}$ & $\begin{array}{l}\text { Desmodium adscendens, Sida } \\
\text { rhombifolia, Vernonia } \\
\text { polyanthes, Stylosanthes } \\
\text { guianensis, Lepidium sativum } \\
\text {, Lactuca sativa, Phleum } \\
\text { pratense, Lolium multiflorum }\end{array}$ & $\begin{array}{l}\text { Germinação, } \\
\text { raiz e } \\
\text { comprimento } \\
\text { de tiro }\end{array}$ & $\begin{array}{l}\text { Souza Filho et } \\
\text { al. ( } 1997 \text { ); } \\
\text { Carvalho et al. } \\
\text { (1993 ); } \\
\text { Kato-Noguchi } \\
\text { et al. ( 2014) }\end{array}$ \\
\hline B. decumbens & $\begin{array}{l}\text { Sementes, brotos } \\
\text { e raízes }\end{array}$ & $\begin{array}{l}\text { Desmodium adscendens, Sida } \\
\text { rhombifolia, Vernonia } \\
\text { polyanthes }\end{array}$ & $\begin{array}{l}\text { Germinação e } \\
\text { comprimento } \\
\text { de raiz }\end{array}$ & $\begin{array}{l}\text { Souza Filho et } \\
\text { al. ( } 1997 \text { ) }\end{array}$ \\
\hline B. humidicola & $\begin{array}{l}\text { Sementes, brotos } \\
\text { e raízes }\end{array}$ & $\begin{array}{l}\text { Desmodium adscendens, Sida } \\
\text { rhombifolia, Vernonia } \\
\text { polyanthes }\end{array}$ & $\begin{array}{l}\text { Germinação e } \\
\text { comprimento } \\
\text { de raiz }\end{array}$ & $\begin{array}{l}\text { Souza Filho et } \\
\text { al. ( } 1997 \text { ) }\end{array}$ \\
\hline
\end{tabular}

Fonte: Adaptado segundo Favaretto et al. (2018).

Tabela 3. Compostos alelopáticos produzidos por Brachiaria spp.

\begin{tabular}{lcl}
\hline \multicolumn{1}{c}{ Espécies } & Aleloquímica & \multicolumn{1}{c}{ Referências } \\
\hline Brachiaria brizantha & $\begin{array}{c}\text { (6R, 9R) }-3-\text {-Oxo- } \alpha \text {-ionol, (6R, 9S) -3- } \\
\text { oxo- } \alpha \text {-ionol, 4-cetopinoresinol }\end{array}$ & $\begin{array}{l}\text { Kato-Noguchi et al. ( } \\
2014)\end{array}$ \\
B. humidicola & Ácido p-cumárico & $\begin{array}{l}\text { Souza Filho et al. ( } \\
2005)\end{array}$ \\
B. mutica & Ferúlico, 2,4-di-hidroxibenzóico, & Chou ( 1989); Chou e \\
& vanílico, p-hidroxibenzóico, p- & Young ( 1975) \\
& hidroxifenilacético, trans-p-cumárico e & \\
& cis-p-cumárico &
\end{tabular}

Fonte: Adaptado segundo Favaretto et al. (2018).

Machado et al. (2011) isolou e identificou em B. mutica, diferentes substâncias com atividade alelopática, como é o caso dos ácidos ferúlico, vanílico, p-hidroxibenzóico e phidroxifenilacético; etileno. Rab et al. (2016), ao estudar o ácido p-cumárico como agente alelopático, também evidenciou intensa atividade alelopática.

Para a espécie Brachiaria mutica, as informações referentes ao isolamento e à identificação de substâncias químicas responsáveis pela atividade alelopática são pouco exploradas, havendo limitadas citações, como é o caso do estudo desenvolvido por Carvalho; Pires (2008), o qual foram isoladas e identificadas as seguintes substâncias químicas com atividade alelopática: ácido ferúlico, ácido 2,4-diidroxibenzóico, ácido vanílico, ácido phidroxibenzóico e ácido $p$-hidroxifenilacético. O referido estudo afirma que o gênero Brachiaria possuiu potencial de atividade alelopática e favoreceu o desenvolvimento de plantas de diferentes espécies por meio da fonte de substâncias químicas. 
Pesquisas atuais afirmam que ocorre redução de nitrogênio em gramíneas, sendo este especialmente sensível à inibição de alelopatia (MOKHTARI et al., 2015). De acordo com Vincensi et al. (2011), as diversas fases do ciclo do nitrogênio são afetadas pela alelopatia, modificando as relações entre o nitrogênio livre, a fixação de nitrogênio e a adição de matéria orgânica.

Existem pesquisas que relatam a interferência da alelopatia na dinâmica do nitrogênio no solo, com objetivo de determinar o potencial alelopático de $B$. decumbens sobre o crescimento inicial de limão-cravo (Citrus limonia), verificando que a incorporação de B. decumbens no solo reduziu drasticamente a quantidade de nitrogênio na solução do solo (OLIVEIRA et al., 2015).

Tem sido abordado nos últimos estudos, que a produção de aleloquímicos é regulada por microrganismos do solo e formação de cadeias carbonadas, visto que os organismos simbiontes apresentam muitas substâncias de utilização biológica, com atividade alelopática, farmacológica, antineoplásica, antimicrobiana, entre outros (RASHIDI et al., 2010).

Tais compostos supracitados estão também envolvidos na interação planta e microrganismos, em especial devido à formação de uma zona química que afeta essa relação. Estudos recentes afirmam que a luteolina foi a primeira molécula identificada envolvida com a indução do gene regulador da fixação de nitrogênio (SANI et al., 2011).

Nesse sentido, poucas informações são encontradas abordando a função dos aleloquímicos e sua interação com bactérias fixadoras de $\mathrm{N}_{2}$. O estudo de plantas com atividade alelopática pode representar excelente oportunidade por proporcionar a possibilidade de fornecer novas direções para entender os motivos da FBN não ser eficaz em Brachiaria.

\subsection{Fixação Biológica do Nitrogênio}

O nitrogênio é considerado o nutriente mais utilizado pela maioria das plantas, sendo constituinte de aminoácidos, proteínas, ácidos nucléicos e clorofila (NADJA et al., 2018.). O ar atmosférico contém cerca de $78 \% \mathrm{~N}_{2}$, no entanto, devido à tripla ligação, é muito estável e indisponível para a maioria dos seres vivos. Somente uma parcela de procariotos, que possuem a enzima nitrogenase, conseguem se beneficiar do $\mathrm{N}$ atmosférico transformando-o em amônia $\left(\mathrm{NH}_{3}\right)$, o qual é incorporado no seu metabolismo. Devido a presença de um complexo enzimático apropriado, capaz de reduzir o $\mathrm{N}_{2}$ a $\mathrm{NH}_{3}$, é que permite que os microrganismos diazotróficos sejam capazes de realizar a FBN. A enzima em questão, a nitrogenase, é constituída por duas unidades proteicas básicas: ferro-proteína e ferromolibdênio. Alguns fatores podem favorecer a inativação da enzima, tais como: disponibilidade energética da célula, disponibilidade de $\mathrm{O}_{2}$, 
excesso de $\mathrm{N}$ e presença de alguns aminoácidos essenciais (MOREIRA; SIQUEIRA, 2006). A figura 2 esquematiza o complexo da enzima nitrogenase.

Figura 2: Complexo da enzima nitrogenase.

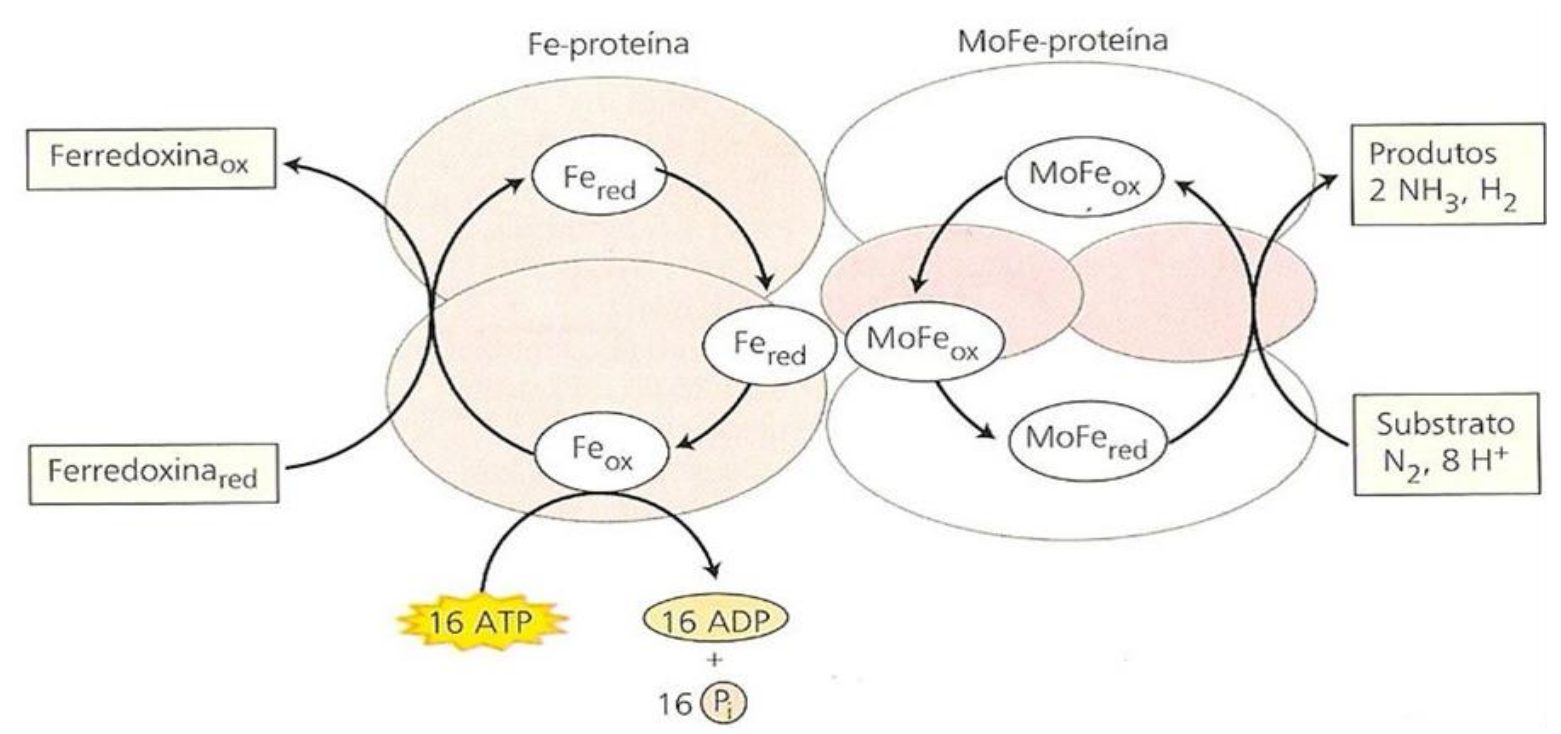

Fonte:http://www.ledson.ufla.br/assimilacao-e-transporte-de-nitrogenio-2/fixacaobiologica-do-nitrogenio$\mathrm{fbn} /$ nitogenase-como-funciona-essa-enzima.

Bactérias que se associam às plantas, colonizando suas raízes, são denominadas rizobactérias, e podem ser classificadas de acordo com seus efeitos sobre o crescimento vegetal: benéficas, deletérias ou neutras (RAB et al., 2016). Quando benéficas, as bactérias colonizam o sistema radicular e promovem o crescimento vegetal, sendo denominadas rizobactérias promotoras de crescimento de plantas (RPCPs) (REPKI et al., 2013).

A interação das bactérias no crescimento das plantas tem sido atribuída a efeitos indiretos associados ao controle biológico de patógenos secundários (BORGES et al., 2014).

$\mathrm{O}$ nitrogênio $(\mathrm{N})$ é um dos compostos mais abundantes da atmosfera, no entanto, se encontra em forma combinada $\left(\mathrm{N}_{2}\right)$ que as plantas e demais organismos eucariotos e uma parcela dos procariotos não conseguem utilizar.

A maior parte de $\mathrm{N}$ nos ecossistemas é decorrente da atividade dos microrganismos diazotróficos, responsáveis pela fixação biológica do nitrogênio (FBN). A FBN é influenciada por diversos fatores, tais como temperatura, umidade, luminosidade, tipo de substrato e disponibilidade de nutrientes (HUNGRIA et al., 2013).

Embora existam relatos de que a FBN seja realizada principalmente pela simbiose de bactérias diazotróficas, as bactérias assimbióticas ou de vida livre, também exercem papel ativo na FBN (QUADROS et al., 2014). Em algumas plantas, não ocorre formação de nódulos nas raízes e as quantidades de $\mathrm{N}$ fixada são muito baixas. 
A abundância relativa das bactérias diazotróficas aeróbias, anaeróbias, anaeróbias facultativas, fotróficas, quimiotróficas e heterotróficas, pode variar de acordo com o ambiente e de fatores ambientais, mencionados anteriormente (HUNGRIA et al., 2011).

A diversidade microbiana pode ser avaliada por técnicas que dependem do cultivo que limitam o estudo de uma pequena parcela da diversidade bacteriana, tais como biomassa microbiana do solo, DNA genômico, sequência DNA, isolamento seletivo. Outro método que pode ser utilizado para avaliação da atividade microbiana são as técnicas moleculares, que consistem em realizar um rastreamento de microrganismos específicos em amostras ambientais, como os microrganismos geneticamente modificados e que possuem a vantagem de permitir acesso a grupos não cultiváveis (REPKE et al., 2013).

\subsection{Fixação Biológica de Nitrogênio em Brachiaria spp.}

Atualmente, existem relatos na literatura de que as vantagens da associação de plantas com bactérias associativas são mais relacionadas à promoção do desenvolvimento vegetal, principalmente do sistema radicular, do que à FBN, embora haja inúmeros relatos que apontam para a viabilidade desse processo (SANDINI et al., 2011; REPKE et al., 2013).

SILVA et al. (2017) no estudo sobre fixação biológica de nitrogênio em pastagens com diferentes intensidades de corte observaram que a contribuição da FBN pelas bactérias diazotróficas nas pastagens variou de 10 a 42\%. Os autores salientaram também que as intensidades de corte não influenciaram na contribuição da FBN em nenhuma das pastagens estudas.

Estudos realizados por Barbosa; Maldonato (2015) trabalhando com Brachiaria brizantha cv. Marandu mostraram que essa gramínea sem aplicação de nitrogênio e com inoculação de bactérias diazotróficas produziu mais forragem do que a testemunha (sem aplicação de $\mathrm{N}$ e sem inoculação).

Tabela 4: Fixação biológica de nitrogênio em pastagens.

\begin{tabular}{llll}
\hline \multicolumn{1}{c}{$\begin{array}{c}\text { Bactérias } \\
\text { diazotróficas }\end{array}$} & \multicolumn{1}{c}{ Forrageiras } & \multicolumn{1}{c}{ Efeito } & \multicolumn{1}{c}{ Autor } \\
\hline Herbaspirillum spp & B. decumbens & Não houve & Boddey et al., 2018 \\
\hline $\begin{array}{l}\text { Azospirillum spp e } \boldsymbol{G} \text {. } \\
\text { diazothrophicus }\end{array}$ & $\begin{array}{l}\text { B. humidicola } \text { e } \\
\text { B. decumbens }\end{array}$ & Efeito negativo & Baldani et al., 2005 \\
\hline $\begin{array}{l}\text { Gluconacetobacter } \\
\text { sp. }\end{array}$ & B. humidicola & $\begin{array}{l}\text { Contribuição de 10 } \\
\text { a 42\% }\end{array}$ & Silva et al., 2017 \\
\hline \multicolumn{2}{c}{ Fonte: Alves et al. (2000) } \\
\hline
\end{tabular}




\subsection{Degradação de Pastagens}

Degradação das pastagens pode ser definida como sendo o processo de perda de vigor, de produtividade, de capacidade de recuperação natural das pastagens para sustentar os níveis de produção e qualidade assim como o de superar os efeitos nocivos de pragas, doenças e invasoras (HUNGRIA et al., 2013). A observação na queda da capacidade, não tem sido suficiente para conscientizar a adoções de ações de manejo, o que tem obrigado à utilização de alternativas de recuperação ou renovação menos viáveis economicamente.

A degradação e a recuperação de áreas degradadas são definidas como atividades de alta complexidade, pois existem inúmeros processos e fenômenos biológicos, físicos e químicos envolvidos no processo (BALVANERA et al., 2012).

Portanto, a recuperação de áreas degradadas deve abordar um conjunto de ações que visam restabelecer as condições de equilíbrio e sustentabilidade em um sistema natural (BIAN; LU, 2013) e esta deve ser realizada de forma multidisciplinar, envolvendo profissionais de diferentes áreas de atuação, para que possa reunir informações, diagnósticos, levantamentos e estudos que permitam a avaliação da degradação ou alteração e a consequente definição de medidas adequadas à recuperação da área.

O termo área degradada, está fortemente associado a ecossistemas alterados, onde ocorreram processos de degradação ambiental. Quando o nível de degradação ainda permite que o ambiente se recupere, ou seja, quando o ambiente mantém sua capacidade de regeneração, considera-se que o ambiente está perturbado e a adoção de medidas intervencionistas pode acelerar o processo de recuperação ambiental. Já quando a degradação não permite a recuperação natural do ambiente, diz-se que o mesmo está degradado, sendo necessárias intervenções para que o mesmo se recupere (BRASIL, 2011).

O termo degradação tem sido, nos últimos relatos, associado a efeitos negativos ou adversos causados ao ambiente que decorrem principalmente devido às atividades antrópicas, sendo raramente utilizado para alterações oriundas de processos naturais (DÉMURGER; PELLETIER, 2015).

A recuperação de pastagens é importante, porque, entre outras razões, evita o desmatamento de novas áreas, além da conservação do solo, recomposição da fertilidade, cobertura do solo, preservação da matéria orgânica do sistema e retenção de água. As vantagens da recuperação de pastagens por meio do manejo adequado da planta forrageira são muitas, entre elas, perenidade do sistema, custo operacional baixo, rapidez no retorno à utilização da pastagem (GALINARI, 2014). 
Os métodos de recuperação de áreas degradadas vêm sofrendo inúmeras mudanças ao longo dos anos, devido à evolução das pesquisas e do surgimento de novas tecnologias, tais como: obrigações legais previstas, técnicas específicas de recuperação de áreas degradadas que visem à recuperação e manutenção de nascente e ressaltar sua importância (DERISSEN et al., 2013). Por este motivo, segundo Eloy et al. (2013), tem ocorrido um crescimento no interesse e na busca por novas alternativas ecológicas de recuperação de áreas degradadas, com ênfase na recomposição da diversidade de espécies no sistema e na sustentabilidade dos ecossistemas recuperados.

Entender o fenômeno da degradação de pastagens e as suas causas é essencial para formular estratégias de recuperação da produtividade dessas áreas, reduzindo, assim, as pressões de desmatamento que visam à formação de novas pastagens (HUNGRIA et al., 2013).

Dada a importância da mitigação de áreas degradadas, o estudo da associação entre Brachiaria spp. e bactérias diazotróficas pode representar excelente oportunidade, visto que é uma interação benéfica. No entanto, a referida associação não está apresentando resultados promissores, e uma das hipóteses é que os compostos alelopáticos liberados pela Brachiaria ssp. podem interferir no estabelecimento da associação (CHAUDHRY et al., 2006; BULEGON et al., 2015).

\section{CONSIDERAÇÕES FINAIS}

Diversos são os gêneros de gramíneas forrageiras tropicais que se apresentam como opções para a formação de pastagens no Brasil. No entanto, verifica-se que grande parte das pastagens se encontram degradadas. A FBN constitui numa das alternativas sustentável e de baixo custo. Entretanto, a contribuição da FBN para o gênero Brachiaria não têm sido tão significativa, quando comparadas à outras espécies vegetais. Dessa forma, os compostos podem interferir na associação entre bactérias diazotróficas e plantas do gênero Brachiaria, reduzindo a eficiência do processo de FBN.

A atividade biológica de um aleloquímico depende tanto da concentração como do limite da espécie afetada. Uma alternativa que vem sendo muito utilizada para os métodos de controle seriam os metabólitos secundários produzidos pelas plantas, que apresentam pouco risco para o ambiente. Diante da importância que os agentes aleloquímicos exercem e à escassez de informações que abordam a relação entre os aleloquímicos e as bactérias fixadoras de $\mathrm{N}$, considera-se relevante discutir sobre a interação dos efeitos alelopáticos da gramínea forrageira Brachiaria spp. com bactérias fixadoras. 


\section{REFERÊNCIAS}

ADAMI, M.et al. Remote sensing time series to evaluate direct land use change of recent expanded sugarcane crop in Brazil. Sustainability, v. 4, n. 4, p. 574-585, 2012.

ALMEIDA FILHO, J. E.et al. Desempenho agronômico e estabilidade fenotípica de híbridos de sorgo granífero. Revista Brasileira de Milho e Sorgo, v. 9, n. 2, p. 51-64, 2010.

ALMEIDA, L.F.R.et al. Non-Oxygenated sesquiterpenes in the essential oil of Copaifera langsdorffii desf. Increase during the day in the dry season. PLOS ONE, v. 11, n. 2, p. 1-12, 2016.

ARMERO, J.et al. 2011. Release of phytoalexins and related isoflavonoids from intact chickpea seedlings elicited with reduced glutathione at root level. Plant. Physiol. Biochem. 39:785-795.

ALVES, B.J.R., et al., Biological nitrogen fixation by two tropical forage legumes assessed from relative ureide abundance of stem solutes ${ }^{15} \mathrm{~N}$ calibration of the technique in sand culture. Nutr. Cycl. Agroecosys., 56: 165-176, 2000.

BALDANI, H.M.; NARVAI, C.P.; ANTUNES, J.F. Plant and soil. Fundação Oswaldo Cruz. v. 18, n. 1-2, p. 755-763, 2012.

BALVANERA, P. et al. Ecosystem services research in Latin America: the state of the art. Ecosystem Services, v. 2, pp. 56-70, 2012.

BARBOSA, J.C.; MALDONADO JUNIOR, W. AgroEstat: sistema para análises estatísticas de ensaios agronômicos. Versão 1.1. Jaboticabal: Departamento de Ciências Exatas, 2010.

BARROS, R.P.et al. LEVANTAMENTO DE PASTAGENS DE PROPRIEDADES RURAIS: CARACTERIZAÇÃO E POSSÍVEIS INTERVENÇÕES. Fórum de Integração Ensino, Pesquisa, Extensão e Inovação Tecnológica do IFRR - e-ISSN 2447-1208, [S.1.], v. 4, n. 2, dez. 2017. ISSN 2447-1208. Disponível

em<https://novoparaiso.ifrr.edu.br/index.php/anais_forint/article/view/539>. Acesso em: 21 ago. 2018.

BATTISTUS, A. G.; INAGAKI, A. M. Componentes de produção e produtividade da cultura da soja submetida à inoculação de bradyrhizobium e azospirillum. Terra Latinoamericana, v. 34, n. 2, p. 169-176, 2016.

BIANCHI, V.J.et al. Marcatori AFLP e SSR, risolutivi nella identificazione genética delle varietá di susino. Frutticoltura, Bologna, n. 4, p. 83-87, 2002.

BIAN, Z.; LU, Q. Ecological effects analysis of land use change in coal mining area based on ecosystem service valuing: a case study in Jiawang. Environmental Earth Sciences, v. 68, n. 6, pp. 1619-1630, 2013.

BODDEY, R.M.; MARCK, B.P.; DAVID, F.H. Plant and soil. Springer Netherlands, v. 311, n. $1-2$, p. $1-18,2018$.

BORELLA J.et al. 2009. Efeito alelopático de extrato aquoso de Persea americana Mill. sobre Lactuca sativa L. Revista Brasileira de Biociências 7: 260-265. 
BORGES, W. L. B.et al. Absorção de nutrientes e alterações químicas em Latossolos cultivados com plantas de cobertura em rotação com soja e milho. Revista Brasileira de Ciência do Solo, v. 38, n. 2 , p. $252-261,2014$.

BULEGON, L.G.et al.Alelopatia de espécies forrageiras sobre a 106 germinação e atividade de peroxidase em alface. Scientia Agraria Paranaensis - SAP; Marechal Cândido Rondon, v. 14, n. 2, abr./jun., p. 94-99, 2015.

BULEGON, L. G. et al. In-furrow inoculation of soybean as alternative to fungicide and micronutrient seed treatment. Revista Brasileira de Ciência do Solo, v.34, p.1103-1112, 2010.

BRASIL. Projeto de Lei no 212 de 2011. Institui o sistema nacional de redução de emissões por desmatamento e degradação, conservação, manejo florestal sustentável, manutenção e aumento dos estoques de carbono florestal $\left(\mathrm{REDD}^{+}\right)$, e dá outras providências. Brasília: Senado, 2011.

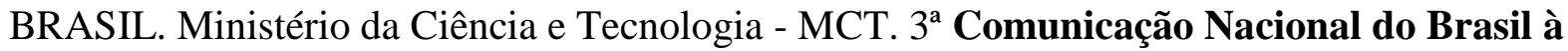
Convenção-Quadro das Nações Unidas sobre Mudança do Clima: volume 3. Brasília, DF, 2016. 336 p. Disponível em:

http://sirene.mcti.gov.br/documents/1686653/1706739/Volume+3.pdf/355d4a1e-9f3c-474a982eb4a63312813b. Acesso em: 10 out 2016.

BROOKS, J. S.; FEENY, P.; Biochem. Syst. Ecol. 2004, 32, 769.

CARVALHO, G.G.P; PIRES, A.J.V. Leguminosas tropicais herbáceas em associação com pastagens. Archivos de Zootecnia, v.57, p.103-113. 2008. Disponível em: Acesso em: 11 maio. 2018 .

CASTRO, C.S.et al. Eficiência de 5537 utilização de adubação orgânica em forrageiras tropicais. Revista de Agricultura 5538 Neotropical, Cassilândia-MS, out./dez. 2016; 3(4): 48-54.

CAZETTA, D. A.et al.Desempenho do arroz de terras altas com a aplicação de doses de nitrogênio e em sucessão às culturas de cobertura do solo em sistema de plantio direto. Bragantia, v. 67, n. 2, p. 471-479, 2008.

CHAUDHRY, N.M.; TARIQ, P. Bactericidal activity of black pepper, bay leaf, aniseed and coriander against oral isolates. Pak J. Pharm. Sci., v.19, n.3, p.214- 218, 2006.

DALEY, C. A.et al. A review of fatty acid profiles and antioxidant content in grass-fed and grain-fed beef. Nutrition Journal, v. 9, n. 10, 2010. Disponível em: . Acesso em: 12 jul. 2018.

DÉMURGER, S.; PELLETIER, A. Volunteer and satisfied? Rural households' participation in a payments for environmental services programme in Inner Mongolia. Ecological Economics, v. 116, pp. 25-33, 2015.

DERISSEN, S.; LATACZ-LOHMANN, U. What are PES? A review of definitions and an extension. Ecosystem Services, v. 6, p. 12-15, 2013.

ELOY, L.; COUDEL, E.; TONI, F. Implementando Pagamentos por Serviços Ambientais no Brasil: caminhos para uma reflexão crítica. Sustentabilidade em Debate, v. 4, n. 1, pp. 21-42, jul./dez. 2013. 
FAVARETTO, A., SCHEFFER-BASSO, SM e PEREZ, NB. Alelopatia em espécies de Poaceae presentes no Brasil. Agron. Sustentar. Dev. (2018) 38: 22. Disponível em: https://doi.org/10.1007/s13593-018-0495-5. Acesso em: 04 outubro. 2018.

FIETZ, C.R.; RANGEL, M.A.S. Época de semeadura da soja para a região de Dourados- MS, com base na deficiência hídrica e no fotoperíodo. Engenharia Agrícola, v. 28, n. 4, p. 666-672, 2008.

FELIX, R. A. Z. Efeito alelopático de extratos de Amburana cearensis (fr. all.) A.C. Smith sobre a germinação e emergência de plântulas. 2012. 100f. Tese (Doutorado em Ciências Biológicas) Instituto de Biociências Botucatu, Universidade Estadual Paulista, SP, 2012.

GALINARI, G. Embrapa mapeia degradação das pastagens do Cerrado. 2014. Disponível em: . Acesso em: 27 jun. 2018.

GASTAL, F.; NELSON, C.J. Nitrogen use within the growing leaf blade of tall fescue. Plant Physiology, v.105, p.191-197, 1994.

HUNGRIA, M. Inoculação com Azospirillum brasilense: inovação em rendimento a baixo custo. Londrina: Embrapa Soja, 2011. 36p.

HUNGRIA, M. et al. Co-inoculation of soybeans and common beans with rhizobia and azospirilla: strategies to improve sustainability. Biology and Fertility of Soils, v.49, p.791-801, 2013.

INSTITUTO BRASILEIRO DE GEOGRAFIA E ESTATÍSTICA. Rebanho efetivo. 2007.

Disponível em: 〈http:// www.ibge.gov.br〉. Acesso em: 15 jan. 2019.

JABRAN, K.et al.Allelopathy for weed control in agricultural systems. Crop Protection, v. 72, n. 1, p. 57-65, 2015.

JORGE, V.S; Souza, F.N.S. Avaliação de diferentes estratégias de uso de agrominerais 5728 na recuperação de áreas degradadas e na produção da pastagem. 2015.

LUVEZUTI, R. A.et al. Eficácia de herbicidas no controle de plantas daninhas e seletividade na cultura do amendoim Runner IAC 886. Revista Brasileira de Herbicidas, v.13, n.3, p.207-215, 2014.

MACHADO, V.et al.Fitossociologia de plantas daninhas em sistemas de integração de sorgo com braquiária sob diferentes formas de implantação da pastagem. Planta Daninha, v. 29, n. 1, p. 8595, 2011.

MATTIELLO, E.M.; et. al. Produção de matéria seca, crescimento radicular e absorção de cálcio, fósforo e alumínio por Coffea canephora e Coffea arabica sob influência da atividade do alumínio em solução. Revista Brasileira de Ciência do Solo, 32, 1/6: 425-434, 2008.

MOREIRA, F. S.; SIQUEIRA, J. O. Microbiologia e bioquímica do solo. 2. ed. Lavras: Ed. da UFLA, 2006.

MOKHTARI KARCHEGANI, H.et al. The effects of nitrogen and water stress on allelopathic potential of sorghum forage on seed germination characteristics and primary growth safflower.

Journal of Oil Plants Production, v. 1, n. 2, p. 79-94, 2015.

Nucleus Animalium, v.11, n.2, nov. 2019 
MOLISCH, H. Der Einfluss einer Pflanze auf die andere Allelopathie. Jena, Fischer. 1937.

NADJA, S. B.; THOMAS W.; FELIZ.T. Nitrogen Fixation Catalyzed by Transition Metal Complexes: Recent Developments. European Journal of Inorganic Chemistry, 2018, $12,(1337-1355)$.

NEVES, A. L. A. et al. Plantio e uso da palma forrageira na alimentação de bovinos leiteiros no semiárido brasileiro. Juiz de Fora: Embrapa Gado de Leite, 7p. n.62,2010.

OLIVEIRA, J.et al. Avaliação de extratos das espécies Helianthus annuus, Brachiaria brizanthae, Sorghum bicolor com potencial alelopático para uso como herbicida natural. Revista. Brasileira de plantas medicinais, v. 17, n. 3, p. 379-384, 2015.

QUADROS, P.D. et al. Desempenho agronômico a campo de híbridos de milho inoculados com Azospirillum. Revista Ceres, v.61, n.2, p.209-218, 2014.

RAB, A.et al. Response of sorghum (Sorghum bicolor L.) extract type, concentration and application time to weeds weight, grain and biomass yield of wheat. Pure and Applied Biology, v. 5, n. 4, p. 847-855, 2016.

RASHID, M. H.; ASAEDA, T.; UDDIN, M. N. The allelopathic potential of kudzu (Pueraria montana). Weed Sci., v. 58, n. 1, p. 47-55, 2010.

REPKE, R.A. et al. Eficiência da Azospirillum brasilense combinada com doses de nitrogênio no desenvolvimento de plantas de milho. Revista Brasileira de Milho e Sorgo, v.12, n.3, p.214226, 2013.

RICE, E.L. Allelopathy. 2nd ed. New York: Academic Press, 1984.

SANDINI, I.E. et al. Efeito residual do nitrogênio na cultura do milho no sistema de produção integração lavoura-pecuária. Ciência Rural, v.41, n.8, p.1315-1322, 2011.

SANI, B. M.et al. Growth, yield and water use efficiency of maize-sorghum intercrop at Samaru, Northern Guinea SAVANNAH, N. N. Journal of Basic and Applied Science, v. 19, n. 2, p. 253-259, 2011.

SILVA, L.M.; VITTI, C.G.; TREVISAM, A.R. Área de Informação da Sede-Artigo em periódico indexado. Pesquisa Agropecuária Brasileira. v. 42, n. 4 , p. 527-535, 2017.

TEODORO, P. E.et al. Phytosociology of weeds in millet under different soil managements in savanna sul-matogrossense. Bioscience Journal, v. 31, n. 4, p. 988-996, 2015.

TOLK, J.A.; HOWELL, T.A.; MILLER, F.R. Yield component analysis of grain sorghum grown under water stress. Field Crops Research, v. 145, n. 1, p. 44-51, 2013.

VINCENSI, M.M.; ARAÚJO, E.O.; KIKUTI, H. Manejo do solo e adubação nitrogenada na supressão de plantas daninhas na cultura do feijão de inverno e irrigado. Revista Ciência Agronômica, v. 42, n. 3, p. 758-764, 2011.

WESTON, L.A.; ALSAADAWI, I.S.; BAERSON, S.R. Sorghum allelopathy: From ecosystem to molecule. Journal of chemical ecology, v. 39, n. 2, p. 142-153, 2013. 